\title{
Feeding Prometheus: An Interdisciplinary Approach for Solving the Global Food Crisis
}

\begin{abstract}
John Vandermeer ${ }^{1,2 *}$, Aniket Aga ${ }^{2,3}$, Jake Allgeier ${ }^{1}$, Catherine Badgley ${ }^{1}$, Regina Baucom ${ }^{1}$, Jennifer Blesh ${ }^{2}$, Lilly F. Shapiro, ${ }^{4,5}$, Andrew D. Jones ${ }^{5}$, Lesli Hoey ${ }^{6}$, Meha Jain ${ }^{2}$, Ivette Perfecto ${ }^{2}$ and Mark L. Wilson ${ }^{5}$

${ }^{1}$ Department of Ecology and Evolutionary Biology, University of Michigan, Ann Arbor, MI, United States, ${ }^{2}$ School for the Environment and Sustainability, University of Michigan, Ann Arbor, MI, United States, ${ }^{3}$ Michigan Society of Fellows, University of Michigan, Ann Arbor, MI, United States, ${ }^{4}$ Sustainable Food Systems Initiative, University of Michigan, Ann Arbor, MI, United States, ${ }^{5}$ School of Public Health, University of Michigan, Ann Arbor, MI, United States, ${ }^{6}$ Taubman School of Urban and Regional Planning, University of Michigan, Ann Arbor, MI, United States
\end{abstract}

\section{OPEN ACCESS}

The current global food system is inadequate to meet the needs of the current world population without compromising future well-being. For example, current intensified

Edited by:

Claire Kremen,

University of California, Berkeley,

United States

Reviewed by:

Albie Felix Miles,

University of Hawaii, United States

Simon Attwood

Bioversity International Headquarers,

Italy

*Correspondence: John Vandermeer jvander@umich.edu

Specialty section: This article was submitted to Sustainable Intensification and

Ecosystem Services,

a section of the journal

Frontiers in Sustainable Food Systems

Received: 04 April 2018

Accepted: 26 June 2018

Published: 23 July 2018

Citation:

Vandermeer J, Aga A, Allgeier J, Badgley C, Baucom R, Blesh J,

Shapiro LF, Jones $A D$, Hoey L, Jain $M$,

Perfecto I and Wilson ML (2018)

Feeding Prometheus: An

Interdisciplinary Approach for Solving

the Global Food Crisis.

Front. Sustain. Food Syst. 2:39.

doi: 10.3389/fsufs.2018.00039 production systems lead to undernutrition in some regions coupled with epidemics of obesity in others while compromising their underlying ecological foundations, such as creating areas of ocean hypoxia. Such common observations challenge the research community to ask new types of basic questions and apply novel analytical frameworks for analyzing them. Elaboration of an integrated applied research agenda is imperative to addressing these global food system challenges. We propose that core competencies of a new analytical framework lie at the intersection of four domains: (1) the ecology of agroecosystems; (2) equity in global and local food systems; (3) cultural dimensions of food and agriculture; and (4) human health. This intersection constitutes a new analytical framework for transitions toward global food system sustainability.

Keywords: agroecology, public health and food, food crisis, food sovereignty, food movement

The allegory of freeing Prometheus, most literally the freeing of humans from the will of celestial deities, is widely used as metaphor for seemingly impossible actions for liberation ${ }^{1}$. The seemingly impossible action of liberating the world from an unsustainable global food system has emerged as a major international environmental and geo-political concern (Heller and Keoleian, 2003; McMichael, 2011; Hunter et al., 2017). Faced with striking contradictions (e.g., dramatic increases in production of some food crops, coupled with coastal marine hypoxia (Nassauer et al., 2007; Diaz and Rosenberg, 2008) and natural resource degradation (Foley et al., 2005); widespread undernutrition in certain regions coupled with an emerging global epidemic of obesity

\footnotetext{
${ }^{1}$ Unchaining Prometheus is a well-worn metaphor for liberating actions, most broadly the freeing of humans from the will of the gods. Because of the crime of stealing fire from Zeus, Prometheus was chained to a rock to be attacked daily by an eagle who ate his liver, which regenerated each day only to invite the eagle once again to the liver, condemning Prometheus to an eternity of suffering. Unchaining him becomes the liberating goal. Our title is inspired by a quote in a different context from playwright Bertold Brecht. "Our audience must experience not only the ways to free Prometheus, but be schooled in the very desire to free him. Theater must teach all the pleasures and joys of discovery, all the feelings of triumph associated with liberation." Essays on the Art of Theater (1954).
} 
(Caballero, 2007; Franklin et al., 2012), both popular and academic analysts have repeatedly warned of an unfolding crisis. Anxiety over global food security and food system sustainability are clearly cause for concern, but, like unchaining Prometheus, addressing such a multi-faceted problem can seem insurmountable. A host of highly focused topics on the global food system is already receiving careful scrutiny, ranging from characterizing the soil microbiome in agricultural systems, to detailed study of the eating habits of preschool and school- aged children, to global food politics and market futures in the context of subsidies and taxation. Such diverse topics are among the many elements in a broad set of interdisciplinary themes that constitute a new and essential challenge for applied academic research-developing a new paradigm for the sustainability of local, regional and the global food system that "puts it all together ${ }^{2}$." Can we "feed" Prometheus, which is to say can we provide the desperately needed intellectual background for the transformation the world needs?

Previous research paradigms isolated component parts of the food system, such as crop production, rural livelihoods, and nutrition patterns, within preexisting disciplines such as agronomy, sociology, or nutritional science. Lack of attention to complex relationships among these and other components of a multi-level, integrated food system contributed to the emergence of the so-called productionist paradigm, which emphasizes yield over broader food system and sustainability goals (Tomlinson, 2013). Such an underlying framework is not wrong on its surface, but is limiting and fails to acknowledge some well-known food-related contradictions and unintended side effects. For example, the world already produces enough edible calories to feed 9 billion people in principle $^{3}$ yet food insecurity is widespread (e.g., 815 million people were chronically undernourished in 2016; FAO et al., 2017). Most current food and agriculture systems worldwide generate diverse environmental concerns (Tilman et al., 2001), yet global diets have become remarkably homogenized (Khoury et al., 2014). Economic inequities continue to deepen for both producers and consumers of food (Borgerhoff Mulder et al., 2009), particularly for small-scale farmers who are still the majority of farmers globally (98\% of all farms, on 53\% of agricultural land; Graeub et al., 2015) and who face increasing threats to their livelihoods (Wiggins et al., 2010). Indeed, the nutritional quality or safety of food continues to deteriorate, contributing in large part to the widespread burden of micronutrient deficiencies and obesity globally (Nestle, 2003). Such problems speak to the mandate for a new environmental, social, and economic paradigm, one that views all elements of food systems as part of a single,

\footnotetext{
${ }^{2}$ Within this sustainability paradigm we of course include issues of resistance and resilience along with other popular framings such as agroecosystem health, food security and food sovereignty (Hoy, 2015; Schipanski et al., 2016).

${ }^{3}$ In the recently published "Beginning to end hunger: Food and the environment in Brazil and beyond" (2017, U. California Press), Chappell makes the simple calculations that, with the recommended 2,300 calories per person per day, and the many estimates of current production at approximately the equivalent of 2,903 calories per day for the current population of 7.25 billion people, elementary calculations show that current production would supply 9.14 billion people with their daily recommended calories, with no other changes in the food system.
}

comprehensive framework. The growth of food systems studies throughout the academy is testament to the emergence of a new scholarly focus that is genuinely interdisciplinary ${ }^{4}$. The subject matter of this new paradigm can be summarized as the intersection of four foci: (1) the ecology of agroecosystems, including all environmental consequences; ${ }^{5}$ (2) equity issues in global and local food systems; (3) cultural dimensions of food and agriculture; and (4) human health, both personal and public.

Agricultural ecology is now a major component of the natural science of ecology more generally, with the agroecosystem viewed as operating within the realm of general ecological principles. Yet the elementary framings of ecology are frequently given short shrift in the design, both formal and informal, of agricultural production systems. Underpinning a new food systems paradigm is the recognition that agroecosystems operate much like other ecosystems. As a result, designing agroecosystems based on ecological science would reduce both external inputs to, and ecological and environmental costs of, crop production. Within this framing, the biodiversity that is planned (agrobiodiversity) and associated (wild biodiversity) is essential for the delivery of ecosystem services (Wood et al., 2015). A broader focus on managing ecological interactions on farms would reduce the negative environmental consequences of agriculture. Especially in the climate-changing Anthropocene, agriculture looms large as either a major contributor to greenhouse gas emissions (10$12 \%$ of all emissions) ${ }^{6}$ or, if performed properly, an important entry point for mitigation and adaptation (Zomer et al., 2016).

Equity issues are essential to solving the food crisis. Availability of food is not the same as access to it. Access to healthy, diverse, affordable food is the crux of food insecurity worldwide, in both urban and rural areas (Ruel et al., 2017). Resolving the dilemma of scarcity within abundance, a major sociopolitical issue of our day, is recognized by many scholars as a difficult but crucial contemporary challenge, highlighting one of the modern system's starkest contradictions-an abundance of food, yet so many millions remaining food insecure (FAO et al., 2017). Closely tied to uneven food access is the widening economic divide among farmers, rooted in the continuing loss of small and mid-sized farms, which are unable to compete in a system that encourages concentration in the agrifood system (Byerlee and Deininger, 2013; Lowder et al., 2016). Further, environmental alterations, such as those resulting from climate change, are expected to affect farmers differentially, with much of the burden

\footnotetext{
${ }^{4}$ Our Sustainable Food System Initiative at the University of Michigan is one such example that includes a broad range of topics. Under the same banner we can cite, for example, the principles of agroecology (Vandermeer and Perfecto), the genetics of herbicide resistance (Baucom), large-scale indirect "planning" of small farms (Hoey, Jain), or the problem of conceptualizing sustainable diets (Jones et al., 2016), among others (see our web page at https://sites.lsa.umich.edu/ sustainablefoodsystems/).

${ }^{5} \mathrm{We}$ aknowledge that transforming the agroecosystem is a major problem that requires a political-economic analysis of the structural connections that perpetuate the current-non-sustainable and inequitable-model and prevents the scaling of agroecological alternatives. A large literature already exists on this issue (Hinrichs, 2014; Sage, 2014; Duru and Therond, 2015; IPES, 2015; DeLonge et al., 2016; Howard, 2016; De Schutter, 2017; Miles et al., 2017; Sanderson Bellamy and Ioris, 2017; Pimbert and Moeller, 2018)
}

${ }^{6}$ IPPC, Fifth Assessment Report, available at http://www.ipcc.ch/report/ar5/ 
falling on smallholder farmers (Morton, 2007) who produce over $50 \%$ of global food production. For these farmers, losses in agricultural production are not only a matter of food security, but also of welfare given that agriculture is a primary form of livelihood for the nearly billion smallholder farmers across the globe.

Food is at the heart of human cultures and therefore culture is an integral component of food system studies. The resources and services provided by local ecosystems, and the knowledges, skills, and meanings that go into managing and sustaining them, contribute significantly to cultural identity and diversity (Richards, 1985; Vasavi, 1999). Cultural dimensions are thus at the heart of what and how food is produced, exchanged and consumed; they mediate the gap between calculations of food calories and peoples' notions of good food and fulfilling agriculture (Mintz and Du Bois, 2002; Counihan and Van Esterik, 2013). After millennia of crop diversification, the globalizing forces of the Anthropocene have generated a tendency toward dietary homogenization, based on a Western diet (Khoury et al., 2014). The concomitant reduction in diversity of food and consequently of some cultures themselves, points to a crisis of democracy evident in contemporary food systems. The need for engaging diverse voices in negotiating the (re)design of local and global food systems is imperative if greater equity and cultural self-determination are to be realized.

Food is also at the heart of human health worldwide. Across the globe, ischemic heart disease, stroke, diabetes and other diet-related non-communicable diseases are top contributors to lost years of healthy life, and are responsible for an enormous economic burden (Murray et al., 2012). In low- and middle-income countries, infectious illnesses

\section{REFERENCES}

Borgerhoff Mulder, M., Bowles, S., Hertz, T., Bell, A., Beise, J., Clark, G., et al. (2009). Intergenerational wealth transmission and the dynamics of inequality in small-scale societies. Science 326, 682-688. doi: 10.1126/science.1178336

Byerlee, D., and Deininger, K. (2013). Growing resource scarcity and global farmland investment. Annu. Rev. Resour. Econ. 5, 13-34. doi: 10.1146/annurev-resource-091912-151849

Caballero, B. (2007). The global epidemic of obesity: an overview. Epidemiol. Rev. 29, 1-5. doi: 10.1093/epirev/mxm012

Counihan, C., and Van Esterik, P. (2013). Food and Culture: A Reader. New York, NY: Routledge.

DeLonge, M. S., Miles, A., and Carlisle, L. (2016). Investing in the transition to sustainable agriculture. Environ. Sci. Policy 55, 266-273. doi: 10.1016/j.envsci.2015.09.013

De Schutter, O. (2017). The political economy of food systems reform. Eur. Rev. Agricul. Econ. 44, 705-731. doi: 10.1093/erae/jbx009

Diaz, R. J., and Rosenberg, R. (2008). Spreading dead zones and consequences for marine ecosystems. Science 321, 926-929. doi: 10.1126/science.1156401

Duru, M., and Therond, O. (2015). Designing agroecological transitions; a review. Agron. Sustain. Dev. 35, 1237-1257. doi: 10.1007/s13593-015-0318-x

FAO, IFAD, UNICEF, WFP and WHO. (2017). The State of Food Security and Nutrition in the World 2017. Building Resilience for Peace and Food Security. Rome: FAO.

Foley, J. A., DeFries, R. S., Asner, G. P., Barford, C., Bonan, G., Carpenter, S. R., et al. (2005). Global consequences of land use. Science 309, 570-574. doi: $10.1126 /$ science. 1111772 and micronutrient deficiencies, linked to unhygienic food preparation and inadequate nutrition, are additional major concerns. Healthy diets remain a goal for all people in all societies, yet obesity and other diet-related diseases are expanding worldwide, although not uniformly. Linking global public health to the type, quality and availability of food is an essential part of the new paradigm.

A global food system that leaves millions food insecure while contributing to obesity, that generates significant collateral environmental degradation, and that compromises the wellbeing of consumers and producers alike challenges the academic community to ask new types of basic research questions and apply novel analytical frameworks for analyzing them. Elaboration of an integrated applied research agenda is imperative to addressing these global food system challenges. We propose that an intersection of the four domains above comprise core competencies of a new analytical framework for transitions toward global food system sustainability. Such structure would inform new, transdisciplinary, and high-impact research questions that will help re-route the food system toward a path of environmental, social, and economic sustainability (Wittman et al., 2017). Unchaining the condemned Prometheus is a liberating goal. We call on the academic community to not only free him, but sustain him with this urgently needed metaphorical food.

\section{AUTHOR CONTRIBUTIONS}

JV wrote the first draft and all other authors contributed in developing the subsequent drafts.
Franklin, B., Jones, A., Love, D., Puckett, S., Macklin, J., and White-Means, S. (2012). Exploring mediators of food insecurity and obesity: a review of recent literature. J. Commun. Health 37, 253-264. doi: 10.1007/s10900-0119420-4

Graeub, B. E., Chappell, M. J., Wittman, H., Ledermann, S., Kerr, R. B., and Gemmill-Herren, B. (2015). The state of family farms in the world. World Dev. 87, 1-15. doi: 10.1016/j.worlddev.2015.05.012

Heller, M. C., and Keoleian, G. A. (2003). Assessing the sustainability of the US food system: a life cycle perspective. Agric. Syst. 76, 1007-1041. doi: 10.1016/S0308-521X(02)00027-6

Hinrichs, C. C. (2014). Transitions to sustainability: a change in thinking about food systems change? Agric. Hum. Values 31, 143-155.

Howard, P. H. (2016). Concentration and Power in the Food System: Who Controls What We Eat? Vol. 3. London: Bloomsbury Publishing.

Hoy, C. W. (2015). Agroecosystem health, agroecosystem resilience, and food security. J. Environ. Stud. Sci. 5, 623-635. doi: 10.1007/s13412-015-0322-0

Hunter, M. C., Smith, R. G., Schipanski, M. E., Atwood, L. W., and Mortensen, D. A. (2017). Agriculture in 2050: recalibrating targets for sustainable intensification. BioScience 67, 386-391. doi: 10.1093/biosci/bix010

IPES (2015). The New Science of Sustainable Food Systems: Overcoming Barriers to Food Systems Reform. First Report of the International Panel of Experts on Sustainable Food Systems.

Jones, A. D., Hoey, L., Blesh, J., Miller, L., Green, A., and Shapiro, L. F. (2016). A systematic review of the measurement of sustainable diets. Adv. Nutr. 7, 641-644. doi: 10.3945/an.115.011015

Khoury, C., Bjorkman, A., Dempewolf, H., Ramirez-Villegas, J., Guarino, L., Jarvis, A., et al. (2014). Increasing homogeneity in global food supplies and the 
implications for food security. Proc. Natl. Acad. Sci. U.S.A. 111, 4001-4006. doi: 10.1073/pnas.1313490111

Lowder, S., Skoet, J., and Raney, T. (2016). The number, size, and distribution of farms, smallholder farms, and family farms worldwide. World Dev. 87, 16-29. doi: 10.1016/j.worlddev.2015.10.041

McMichael, P. (2011). Food system sustainability: questions of environmental governance in the new world (dis) order. Global Environ. Change 21, 804-812. doi: 10.1016/j.gloenvcha.2011.03.016

Miles, A., DeLonge, M. S., and Carlisle, L. (2017). Triggering a positive research and policy feedback cycle to support a transition to agroecology and sustainable food systems. Agroecol. Sustain. Food Syst. 41, 855-879. doi: 10.1080/21683565.2017.1331179

Mintz, S. W., and Du Bois, C. M. (2002). The anthropology of food and eating. Annu. Rev. Anthropol. 31, 99-119. doi: 10.1146/annurev.anthro.32.032702.131011

Morton, J. (2007). The impact of climate change on smallholder and subsistence agriculture. Proc. Natl. Acad. Sci. U.S.A. 104, 19680-19685. doi: 10.1073/pnas.0701855104

Murray, C. J., Vos, T., Lozano, R., Naghavi, M., Flaxman, A. D., Michaud, C., et al. (2012). Disability-adjusted life years (DALYs) for 291 diseases and injuries in 21 regions, 1990-2010: a systematic analysis for the Global Burden of Disease Study 2010. Lancet 380, 2197-2223. doi: 10.1016/S0140-6736(12)61689-4

Nassauer, J. I., Santelmann, M. V., and Scavia, D. (eds.). (2007). From the Corn Belt to the Gulf: Societal and Environmental Implications of Alternative Agricultural Futures. London: Earthscan.

Nestle, M. (2003). The ironic politics of obesity. Science 299, 781-781. doi: 10.1126/science.299.5608.781

Pimbert, M. P., and Moeller, N. I. (2018). Absent agroecology aid: on UK agricultural development assistance since 2010. Sustainability 10:505. doi: $10.3390 /$ su10020505

Richards, P. (1985). Indigenous Agricultural Revolution: Ecology and Food Production in West Africa. London: Hutchison.

Ruel, M. T., Garrett, J., Yosef, S., and Olivier, M. (2017). "Urbanization, food security and nutrition," in Nutrition and Health in a Developing World. Nutrition and Health, eds S. de Pee, D. Taren, and M. Bloem (Cham: Humana Press), 705-735.

Sage, C. (2014). The transition movement and food sovereignty: from local resilience to global engagement in food system transformation. J. Consum. Cult. 14, 254-275. doi: 10.1177/1469540514526281
Sanderson Bellamy, A., and Ioris, A. A. R. (2017). Addressing the knowledge gaps in agroecology and identifying guiding principles for transforming conventional agri-food systems. Sustainability 9:330. doi: 10.3390/su9030330

Schipanski, M. E., MacDonald, G. K., Rosenzweig, S., Chappell, M. J., Bennett, E. M., Kerr, R. B., et al. (2016). Realizing resilient food systems. BioScience 66, 600-610. doi: 10.1093/biosci/biw052

Tilman, D., Fargione, J., Wolff, B., D’Antonio, C., Dobson, A., Howarth, R., et al. (2001). Forecasting agriculturally driven global environmental change. Science 292, 281-284. doi: 10.1126/science. 1057544

Tomlinson, I. (2013). Doubling food production to feed the 9 billion: a critical perspective on a key discourse of food security in the UK. J. Rural Stud. 29, 81-90. doi: 10.1016/j.jrurstud.2011.09.001

Vasavi, A. R. (1999). Harbingers of Rain: Land and Life in South India. New Delhi: Oxford University Press.

Wiggins, S., Kirsten, J., and Llambí, L. (2010). The future of small farms. World Dev. 38, 1341-1348. doi: 10.1016/j.worlddev.2009.06.013

Wittman, H., Chappell, M. J., Abson, D. J., Kerr, R. B., Blesh, J., Hanspach, J., et al. (2017). A social-ecological perspective on harmonizing food security and biodiversity conservation. Reg. Environ. Change 17, 1291-1301. doi: 10.1007/s10113-016-1045-9

Wood, S. A., Karp, D. S., DeClerck, F., Kremen, C., Naeem, S., and Palm, C. A. (2015). Functional traits in agriculture: agrobiodiversity and ecosystem services. Trends Ecol. Evol. 30, 531-539. doi: 10.1016/j.tree.2015.06.013

Zomer, R. J., Neufeldt, H., Xu, J., Ahrends, A., Bossio, D., Trabucco, A., et al. (2016). Global Tree Cover and Biomass Carbon on Agricultural Land: the contribution of agroforestry to global and national carbon budgets. Sci. Rep. 6:29987. doi: 10.1038/srep29987

Conflict of Interest Statement: The authors declare that the research was conducted in the absence of any commercial or financial relationships that could be construed as a potential conflict of interest.

Copyright (c) 2018 Vandermeer, Aga, Allgeier, Badgley, Baucom, Blesh, Shapiro, Jones, Hoey, Jain, Perfecto and Wilson. This is an open-access article distributed under the terms of the Creative Commons Attribution License (CC BY). The use, distribution or reproduction in other forums is permitted, provided the original author(s) and the copyright owner(s) are credited and that the original publication in this journal is cited, in accordance with accepted academic practice. No use, distribution or reproduction is permitted which does not comply with these terms. 